\title{
Efficiency and Effectiveness Concepts Applied in Shell and Tube Heat Exchanger Using Ethylene Glycol-Water Based Fluid in the Shell with Nanoparticles of Copper Oxide (CuO)
}

\author{
Élcio Nogueira $(1)$ \\ Departamento de Engenharia Mecânica e Energia da Universidade do Estado do Rio de Janeiro, DME/FAT/UERJ, Resende, Brazil \\ Email: elcionogueira@hotmail.com
}

How to cite this paper: Nogueira, É. (2020) Efficiency and Effectiveness Concepts Applied in Shell and Tube Heat Exchanger Using Ethylene Glycol-Water Based Fluid in the Shell with Nanoparticles of Copper Oxide $(\mathrm{CuO})$. Journal of Materials Science and Chemical Engineering, 8, 1-12.

https://doi.org/10.4236/msce.2020.88001

Received: July 6, 2020

Accepted: August 15, 2020

Published: August 18, 2020

Copyright $\odot 2020$ by author(s) and Scientific Research Publishing Inc. This work is licensed under the Creative Commons Attribution International License (CC BY 4.0).

http://creativecommons.org/licenses/by/4.0/

\begin{abstract}
This article consists of an analytical solution for obtaining the outlet temperatures of the hot and cold fluids in a shell and tube heat exchanger. The system analyzed through the concepts of efficiency, effectiveness $(\varepsilon-N T U)$, and irreversibility consisted of a shell and tube heat exchanger, with cold nanofluid flowing in the shell and hot water flowing in the tube. The nanofluid consists of 50\% of ethylene glycol and water as the base fluid and copper oxide $(\mathrm{CuO})$ nanoparticles in suspension. The volume fractions of the nanoparticles range from 0.1 to 0.5 . The flow rate in the nanofluid ranges from 0.0331 to $0.0568 \mathrm{Kg} / \mathrm{s}$, while two mass flow rates, from 0.0568 and $0.5 \mathrm{Kg} / \mathrm{s}$, for the hot fluid, are used as parameters for analysis. Results for the efficiency, effectiveness, irreversibility, heat transfer rate, and outlet temperatures for cold and hot fluids were obtained graphically. The flow laminarization effect was observed through the results obtained and had significant relevance in the results.
\end{abstract}

\section{Keywords}

Efficiency, Effectiveness, Shell and Tube Heat Exchanger, Nanofluid, Ethylene Glycol

\section{Introduction}

It is an analytical solution to analyze the effects on the outlet temperature of a hot fluid that flows in the tube and exchanging heat with a cold nanofluid that flows in the housing, using concepts of efficiency, effectiveness, and irreversibility.

Equipment that allows heat exchange between two fluids, separated or not by a solid medium, is commonly called heat exchangers. Among the existing heat ex- 
changers, shell and tube heat exchangers stand out.

Heat exchangers shell and tube type usually use baffles. The baffles change the direction of flow on the side of the shell to ensure high heat transfer rates and provide support for the tube bundles. Also, they play an essential role in hydrodynamics and thermal performance.

In this work, the interest is in the heat exchange between fluids consisting of cold water in the tube and hot nanofluid in the shell. The nanofluid consists of 50\% of ethylene glycol and water as the base fluid and suspension of copper oxide $(\mathrm{CuO})$ nanoparticles.

Based on the first law and the second law of thermodynamics, the analysis focuses mainly on the outlet temperature of the water to be cooled using the efficiency, effectiveness, and irreversibility concepts.

There are many reports in the specialized literature related to shell and tube type heat exchangers based on the second reading of thermodynamics. The efficiency of a system is based on thermal irreversibility and viscous dissipation.

One of the first authors to use the concept of efficiency and entropy in heat exchanger systems, in a comprehensive and detailed review, was Adrian Bejan [1]. The survey analyzes the fundamental mechanisms responsible for the generation of entropy in the heat and fluid flow. He discusses ways to balance the irreversibility of the heat transfer and the irreversibility of the fluid flow.

Ahmad Fakheri [2] analyzes and uses the second law of thermodynamics to provide the solution to the problem of defining thermal efficiency for heating in heat exchangers. He demonstrated that the ideal heat exchanger has the same ratio of inlet temperature from cold to hot fluid, the same difference in logarithmic average temperature, generates the minimum amount of entropy, and it is the most efficient and least irreversible. The actual heat transfer is achieved by multiplying the efficiency and the optimum heat transfer rate provided by the UA product and the arithmetic average temperature difference. His work presented a new way of analyzing heat exchangers.

Roopesh Tiwari and Govind Maheshwari [3] determine the maximum efficiency of a heat exchanger corresponding to the rate of heating capacity and use the efficiency concept based on fin analogy. They point out that the effectiveness does not provide any information about the efficiency of the heat exchange that occurs in a heat exchanger and that the optimum performance of the counter flow arrangement based on effectiveness and efficiency is obtained for the heat capacity ratio around $\mathrm{R}=0.5$.

Qazizada Mohammad Emal and Pivarciova Elena [4] perform experimental work and use the formulation of a global energy balance in a shell and tube heat exchanger to study heat losses. They focus on studying heat transfer in the countercurrent flow to measure the temperature profile in a shell and tube heat exchanger. They compare the performances of the heat exchanger, using the countercurrent flow and parallel flow arrangements, based on the first law of thermodynamics.

Karthik Silaipillayarputhur and Hassan Khurshid [5] considered a review for 
the design of a shell and tube heat exchanger. They point out that the heat exchanger must deliver the required heat transfer, occupy less space, and weigh less.

Amir Qashqaei and Ramin Ghasemi Asl [6] compare the characteristics of heat transfer and pressure drop in a flow of nanofluid consisting of copper oxide $(\mathrm{CuO})$ and water in a helical heat exchanger. They claim that nanofluids have higher coefficients of thermal conductivity and diffusivity. They concluded that with the use of copper oxide $(\mathrm{CuO})$, the heat exchanger based on nanofluid is effective in improving thermal efficiency.

Ms. Sivahari Shankar, P. Immanuel, and M. Eswaran [7] performed an experimental study of the heat transfer characteristic of the water and $\mathrm{Al}_{2} \mathrm{O}_{3}$ nanoparticles that flows inside the shell of one shell and tube heat exchanger. The experiments were conducted with the Reynolds number in the tubes varying from 1700-9500. They conclude that the application of nanofluid in the shell, compared to water, improves the overall heat transfer coefficient of the shell and tube heat exchanger.

Rahul Mahajan et al. [8] use $\mathrm{Al}_{2} \mathrm{O}_{3}$ /water nanofluid with particle varying in the range of $0.01 \%-0.3 \%$ in the shell and tube heat exchanger in an experimental procedure. They conclude that the dispersion of nanoparticles into the distilled water increases the thermal conductivity and viscosity of the nanofluids and enhances the conduction as well as convection rate. More considerable temperature differences will occur by using nanofluids.

Priyanka S. Gore and Jagdeep M. Kshirsagar [9] present one paper is to review theoretical investigations and experimental using $\mathrm{Al}_{2} \mathrm{O}_{3}$ nanofluid with twisted tapes incorporated in tubes of shell \& tube heat exchanger. They conclude that the swirl flow, caused the twisted tape, enhances the heat transfer coefficient considerably, and justify the use because the energy consumption optimization becomes important.

\section{Methodology}

The equations presented below and some demonstrations can be obtained through the following references: Adrian Bejan [1], Ahmad Fakheri [2], Roopesh Tiware and Govind Maheswari [3], Karthik Silaipillay [5], Amir Qashoaei and Ramin Ghasemi Asl [6], Élcio Nogueira [10], Luiz Carlos Cordeiro Junior and Élcio Nogueira [11] and Nogueira E. [12]. Schematic representation of the Shell and Tube Heat Exchanger (Figure 1) and Properties of the fluids and nanoparticles (Table 1) are given below.

Basic data: $L_{S}=0.762 \mathrm{~m} ; d_{S}=0.508 \mathrm{~m} ; d_{T}=0.0127 \mathrm{~m} ; T c_{i}=27^{\circ} \mathrm{C} ; T h_{i}=90^{\circ} \mathrm{C}$; $N_{T}=32$; one pass in the tube, one pass in the shell and 3 baffles.

If the volume fraction $\left(V_{E G}\right)$ of ethylene glycol is provided, the properties of the base fluid can be obtained through the equations below:

$$
\begin{aligned}
& \mu_{\text {solution }}=\mu_{E G} V_{E G}+\left(1-V_{E G}\right) \mu_{w c} \\
& \rho_{\text {solution }}=\rho_{E G} V_{E G}+\left(1-V_{E G}\right) \rho_{w c} \\
& k_{\text {solution }}=k_{E G} V_{E G}+\left(1-V_{E G}\right) k_{w c}
\end{aligned}
$$




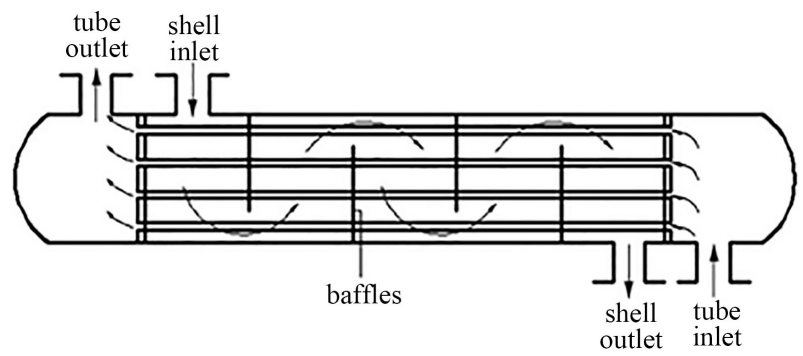

Figure 1. The basic configuration of Shell and Tube.

Table 1. Properties of the fluids and nanoparticles.

\begin{tabular}{ccccc}
\hline & Shell Cold Fluid & Tube Hot Fluid & CuO & EG50\% \\
\hline $\boldsymbol{k} \mathrm{W} /\left(\mathrm{m}^{\circ} \mathrm{C}\right)$ & 0.60 & 0.67 & 400 & 1830.4223 \\
$C \boldsymbol{p} \mathrm{J} /\left(\mathrm{kg}{ }^{\circ} \mathrm{C}\right)$ & 4180 & 4216 & 8933 & 3878.9317 \\
$\mu \mathrm{kg} /(\mathrm{m} \mathrm{s})$ & $0.75810^{-3}$ & $0.303110^{-3}$ & - & $5.27798310^{-4}$ \\
$\rho \mathrm{kg} / \mathrm{m}^{3}$ & 997 & 970 & 385 & 1058.33 \\
$\nu \mathrm{m}^{2} / \mathrm{s}$ & $0.810-6$ & $0.33410^{-6}$ & - & $4.98710^{-7}$ \\
$\boldsymbol{\alpha} \mathrm{m}^{2} / \mathrm{s}$ & $1.43010^{-7}$ & $1.68010^{-7}$ & $1.16310^{-4}$ & $4.86510^{-4}$ \\
$\boldsymbol{P r}$ & 5.68 & 1.98 & - & 975.49 \\
\hline & $C p_{\text {solution }}=C p_{E G} V_{E G}+\left(1-V_{E G}\right) C p_{w c}$ &
\end{tabular}

The properties of the nanofluid, for volume fraction $(\phi)$ of the Copper Oxide $(\mathrm{CuO})$, is given by the following equations:

$$
\begin{gathered}
\rho_{c}=\phi \rho_{\text {solution }}+(1-\phi) \rho_{\text {solution }} \\
\mu_{c}=\mu_{\text {solution }}\left(1-0.19 \phi+306 \phi^{2}\right) \\
C p_{c}=\left(\phi \rho_{\text {particle }} C p_{\text {particle }}+(1-\phi) \rho_{\text {solution }} C p_{\text {solution }}\right) / \rho \\
k_{c}=\left[\frac{k_{\text {particle }}+2 k_{\text {solution }}+2\left(k_{\text {particle }}-k_{\text {solution }}\right)(1-0.1)^{3} \phi}{k_{\text {particle }}+2 k_{\text {solution }}+2\left(k_{\text {particle }}-k_{\text {solution }}\right)(1+0.1)^{2} \phi}\right] k_{\text {solution }}
\end{gathered}
$$

The heat exchange area is obtained by:

$$
\begin{gathered}
A_{h}=\pi d_{T} L_{S} N_{T} \\
R e_{h}=4\left(\dot{m}_{h} / N_{T}\right) / \pi d_{T} \mu_{h}
\end{gathered}
$$

$R e_{h}$ is the Reynolds number in the tube, and

$$
N u_{h}=4.364+0.0722 \operatorname{Re}_{h} P r_{h} \frac{d_{T}}{L_{S}} \text { for } R e_{h}<2100
$$

or

$$
N u_{h}=0.023 \operatorname{Re}_{h}^{0.8} \mathrm{Pr}_{h}^{0.4}
$$

are the Nusselt number in the tube.

Then the convective heat transfer coefficient in the tube is given by: 


$$
\begin{gathered}
h_{h}=\frac{N u_{h} k_{h}}{d_{T}} \\
R e_{c}=\frac{4 m_{c}}{\pi d_{e} \mu_{c}}
\end{gathered}
$$

$R e_{h}$ is the Reynolds number in the shell, and

$$
N u_{c}=4.364+0.0722 \operatorname{Re}_{c} P r_{c} \frac{d_{e}}{L_{s}} \text { for } R e_{c}<2100
$$

or

$$
N u_{c}=0.023 R e_{c}^{0.8} \operatorname{Pr}_{c}^{0.3}
$$

are the Nusselt number in the shell.

At where, $d_{e}$ is the shell equivalent diameter:

$$
d_{e}=\frac{1.27}{d_{T}}\left(P_{T}^{2}-0.785 d_{T}^{2}\right)
$$

Then, the convection heat transfer coefficient in the shell is:

$$
\begin{gathered}
h_{c}=\frac{N u_{c} K_{c}}{d_{e}} \\
P_{T}=1.25 d_{T}
\end{gathered}
$$

$P_{T}$ is the tube pitch, for square pitch.

$$
\begin{gathered}
D_{B}=d_{S}\left(\frac{N_{T}}{0.125}\right)^{\frac{1}{2.207}} \\
B_{S}=0.4 D_{B}
\end{gathered}
$$

$D_{B}$ and $B_{S}$ are, respectively, the bundle diameter and baffles space.

The number of baffles is given by:

$$
B_{B}=\frac{L_{S}}{B_{S}}
$$

The overall convection heat transfer coefficient:

$$
U_{O}=\frac{1}{\frac{1}{h_{h}}+\frac{1}{h_{c}}}
$$

The thermal capacities of both fluids are given by:

$$
\begin{gathered}
C_{c}=\dot{m}_{c} C p_{c} \text { and } C_{h}=\dot{m}_{h} C p_{h} \\
\mathrm{NTU}=\frac{A_{h} U_{O}}{C_{\min }}
\end{gathered}
$$

NTU is the Number of Thermal Units, at where, $C_{\min }$ is the lowest value among thermal capacities.

$$
\varepsilon=\frac{1}{\frac{1}{\eta \mathrm{NTU}}+\frac{1+C^{*}}{2}}
$$


$(\varepsilon)$ is the effectiveness of the shell and tube heat exchanger [2] [3].

$$
\eta=\frac{\operatorname{Tanh}\left(F_{a}\right)}{F_{a}}
$$

$(\eta)$ is the efficiency of the heat exchanger is [2] [3], at where,

$$
F_{a}=\frac{\mathrm{NTU}\left(1-C^{*}\right)}{2}
$$

and

$$
C^{*}=\frac{C_{\max }}{C_{\min }}
$$

The heat transfer rate, depending on the efficiency and temperature of the fluids, is obtained by [2]:

$$
Q_{\text {Actual }}=\frac{\left(T h_{i}-T c_{i}\right) C_{\text {min }}}{\frac{1}{\eta \mathrm{NTU}}+\frac{1+C^{*}}{2}}
$$

The maximum heat transfer rate is,

$$
\begin{gathered}
Q_{\max }=C_{\min }\left(T h_{i}-T c_{i}\right) \\
T h_{O}=T h_{i}-\frac{Q_{\text {Actual }}}{\dot{m}_{h} C p_{h}}
\end{gathered}
$$

and

$$
T c_{O}=T c_{i}+\frac{Q_{\text {Actual }}}{\dot{m}_{c} C p_{c}}
$$

$T h_{O}$ and $T c_{O}$ are the outlet temperatures,

Finally, the thermal irreversibility is given by [1]:

$$
\sigma_{T}=\frac{C_{h}}{C_{\min }} \ln \left(\frac{T h_{O}}{T h_{i}}\right)+\frac{C_{c}}{C_{\min }} \ln \left(\frac{T c_{O}}{T c_{i}}\right)
$$

\section{Results and Discussion}

Fluid enters the tube at $90^{\circ} \mathrm{C}$ and the shell at $27^{\circ} \mathrm{C}$. The flow in the shell varies from $0.0331 \mathrm{~kg} / \mathrm{s}$ to $0.2324 \mathrm{~kg} / \mathrm{s}$. Two flow rates in the tube, $0.0568 \mathrm{~kg} / \mathrm{s}$ and 0.5 $\mathrm{kg} / \mathrm{s}$, and fractions in the volume of copper oxide ranging from 0.1 to 0.5 were considered for analysis.

The phenomenon of flow laminarization, as already observed by Nogueira E. (2020), is shown in Figure 2. The number of Reynolds is smaller for more significant fractions of nanoparticles for the same flow rate of the cold fluid since there is an increase in the viscosity of the nanofluid. This increase is a fact that has repercussions on momentum and heat exchange.

Figure 3 shows the results obtained for the efficiency of the heat exchanger as a function of the Reynolds number in the shell, using the flow parameters and 
volume fractions, already specified, of the hot fluid. Again, one can observe the phenomenon of flow laminarization for high volume fractions of copper oxide. In these cases, the Reynolds number decreases to the same mass flow rate of the cold fluid, as the viscosity increase. For flow rates in the tube equal to $0.0568 \mathrm{~kg} / \mathrm{s}$, the efficiency is significantly high for all volume fractions of copper oxide.

The fraction in a volume equal to 0.1 stands out. In this situation, the efficiency presents high values in all Reynolds number range, and for the two hot fluid flow rates considered. For fraction in a volume equal to 0.5 and the flow rate in the tube corresponding to $0.5 \mathrm{~kg} / \mathrm{s}$, the efficiency drops significantly in the low number of Reynolds.

Two aspects must be considered for high efficiency for the low value of the volume fraction of copper oxide and low flow rate for the hot fluid: the increased diffusivity of the nanofluid, associated with the most prominent Brownian movement, and the longer time of the heated fluid in the tube. These two aspects contribute to the heat exchange to approach the maximum possible for the conditions imposed on the flow rate in the shell and tube.

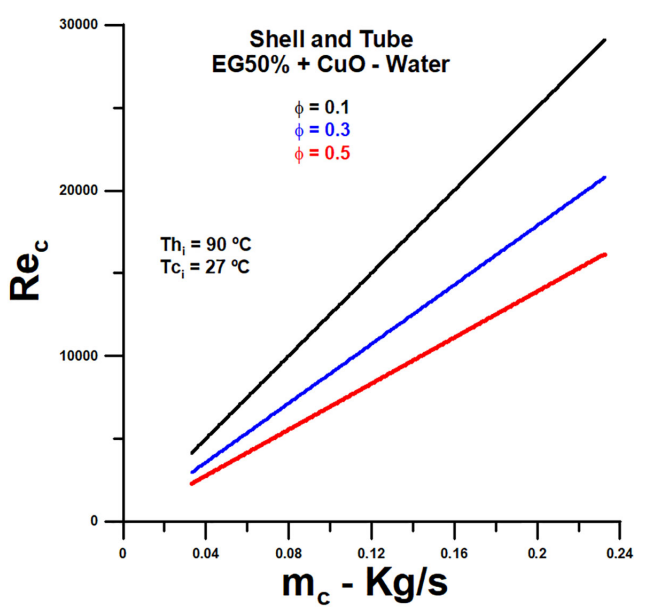

Figure 2. Reynolds number versus mass flow rate in the shell.

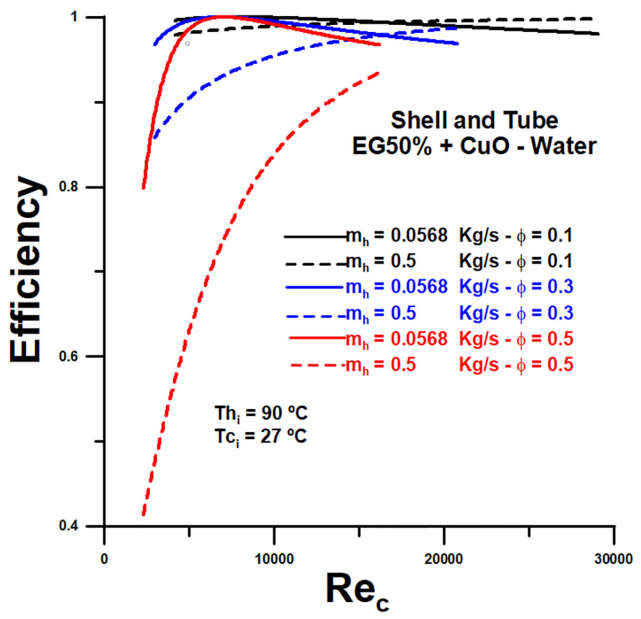

Figure 3. Efficiency versus Reynolds number in the shell. 
Figure 4 shows the results for effectiveness. In this case, there is a contrast about efficiency, since, under conditions where there is a high efficiency, low effectiveness occurs. The effectiveness is higher for high water flows in the pipe and a high concentration of copper oxide. According to the laminarization phenomenon, there is an abrupt increase in effectiveness to a Reynolds number close to 10,000 for low fluid flow rates in the tube. This fact can be justified due to the change in the value of the minimum thermal capacity.

As the flow rate of the cold fluid increases, its thermal capacity also increases until it overlaps the value of the thermal capacity of the hot fluid in the pipe. The phenomenon is not observed for the high flow rate of the heated fluid since within the range of flow values of the cold fluid, considering there is no alternation of the minimum thermal capacity.

The irreversibility related to the thermal exchange, Figure 5, presents low values where the efficiency is high, as expected. The trend observed for the values of irreversibility, about efficiency, is the same as that of effectiveness, and it also increases significantly when the minimum thermal capacity changes in value. The smallest fraction of nanoparticles allows low irreversibility, even for a high number of Reynolds for cold fluid. Evidently, in this case, higher diffusivity is favored by turbulent flow. For the low flow rate of the hot fluid, it is preferable to use a flow rate of the cold fluid in which the Reynolds number is close to 10,000 , whatever the volume fraction of the nanoparticles.

The heat transfer rate, Figure 6, presents relatively higher values for greater mass flow in the tube. Also, observable, the heat transfer rate is higher as the fraction of nanoparticles and the mass flow of the fluid in the hull increase.

Through Figure 7, we present the maximum heat transfer rate as a function of the Reynolds number in the cold fluid and for fractions in the volume of nanoparticles ranging from 0.1 to 0.5 for two different mass flow rates in the tube. For the low mass flow rate in the tube, the heat transfer rate is the maximum possible within the Reynolds number range considered in the analysis. The same does not happen for higher mass flow in the tube, that is, for mass flow equal to $0.5 \mathrm{Kg} / \mathrm{s}$. As can be seen in the highlight, the maximum possible exchange is not achieved for the Reynolds number range considered in the analysis, and for high mass flow in the tube. It is possible to anticipate, observing Figure 3 and Figure 7, that there is an excellent relationship with the maximum possible heat exchange and the efficiency of the system, since the optimum efficiency, for low mass flow in the pipe, occurs between the Reynolds numbers between 5000 and 10,000.

Figure 8 and Figure 9 show the outlet temperatures for the cold and hot fluid, respectively.

The outlet temperature of the cold fluid is high when the heat transfer rate, the effectiveness, and the irreversibility are high.

The outlet temperature of the hot fluid is lower when the efficiency is higher, the heat transfer rate and effectiveness are the maximum possible, that is, for the lowest flow rates in the tube, equal to $0.0568 \mathrm{~kg} / \mathrm{s}$. Also, the lowest outlet temperature is obtained when the copper oxide fraction is the highest within the 
range of values analyzed. It can be seen, through Figure 3 and Figure 4, for this situation, the lower temperature of the hot fluid occurs when the efficiency is maximum, and the effectiveness is high.

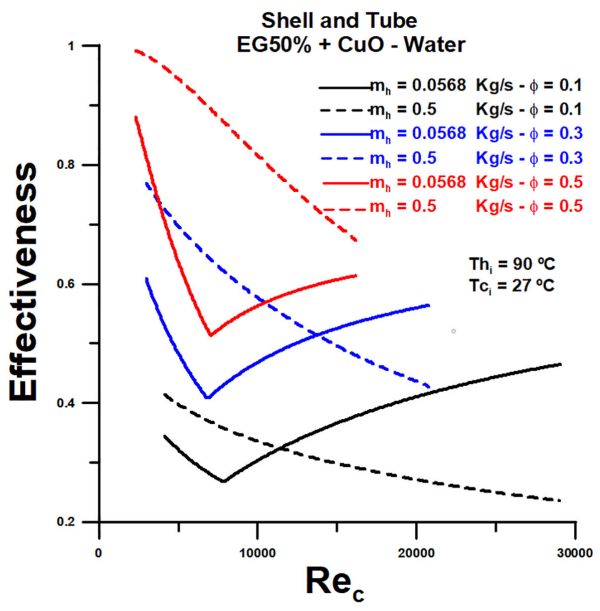

Figure 4. Effectiveness versus Reynolds number in the shell.

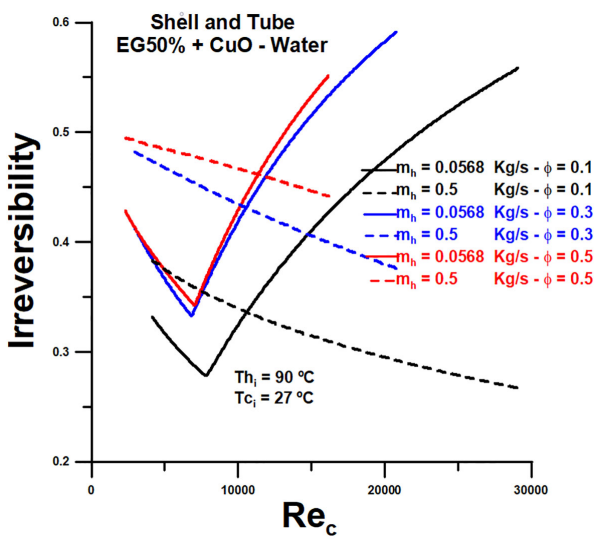

Figure 5. Irreversibility versus Reynolds number in the shell.

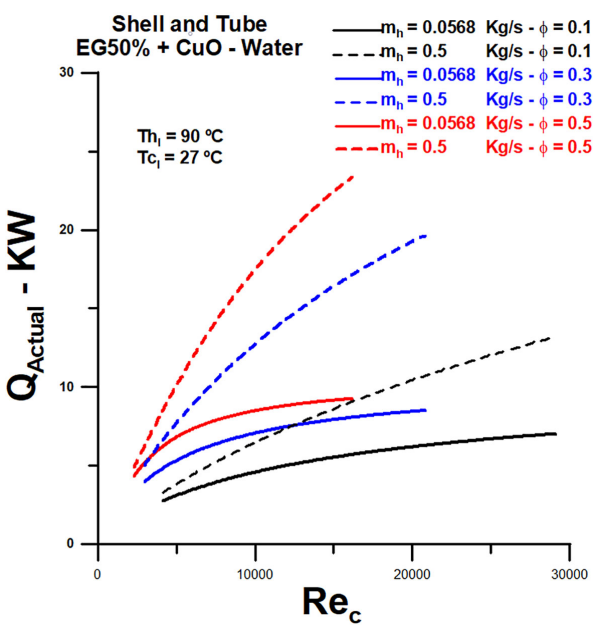

Figure 6. Heat Transfer rate (QActual) versus Reynolds number in the Shell. 


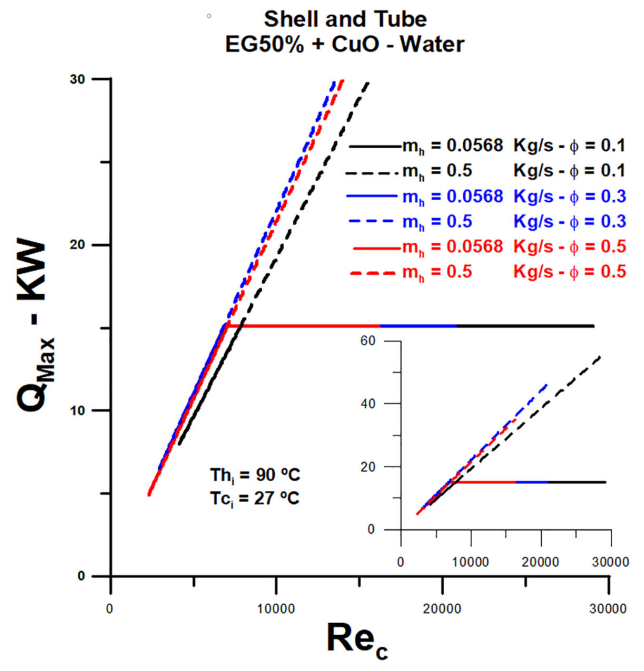

Figure 7. Heat Transfer rate (QMax) versus Reynolds number in the Shell.

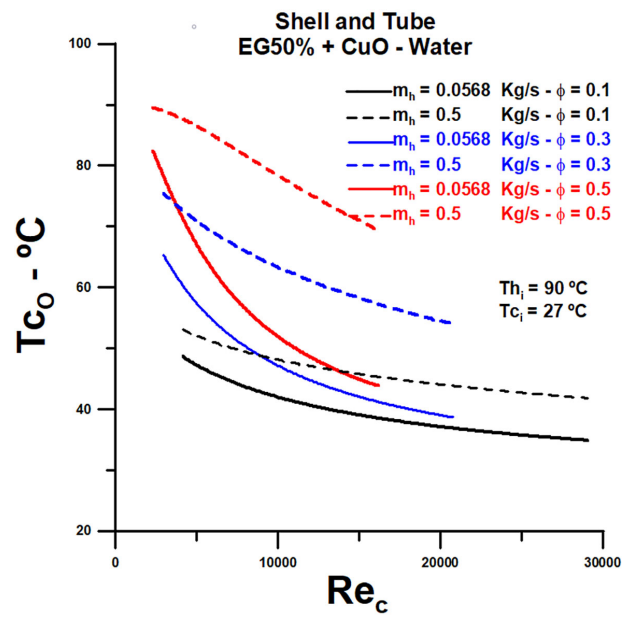

Figure 8. Outlet temperature of the cold fluid versus Reynolds number in the shell.

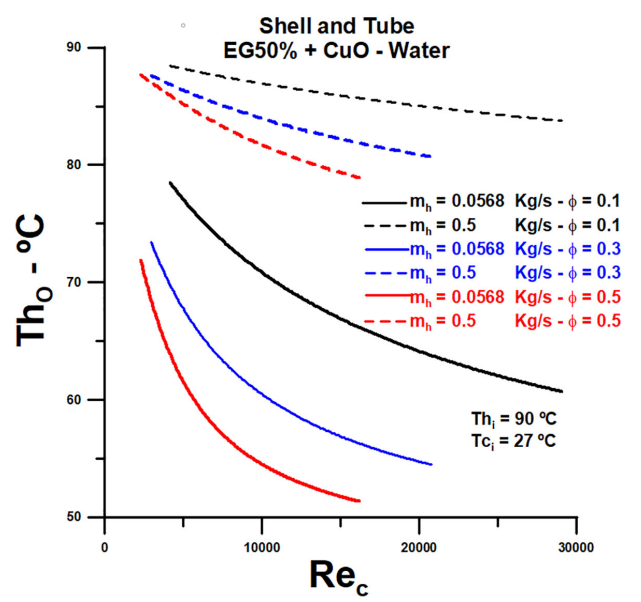

Figure 9. Outlet temperature of the hot fluid versus Reynolds number in the shell. 
For the higher mass flow rate of the hot fluid, the outlet temperatures of the hot fluid are not favorable for the entire range of fractions in the volume of the nanoparticles analyzed. In this case, thermal irreversibility, which is a measure of heat dissipation, is high, as is the rate of heat transfer, but not equal to the maximum.

High efficiency occurs for low mass flow of the hot fluid and smaller volume fraction for the nanoparticles. On the other hand, for the same situation, we have low effectiveness and irreversibility, and consequently, a higher outlet temperature of the hot fluid

\section{Conclusions}

The results show that it is not enough to have high effectiveness, which represents a more significant rate of heat exchange if the efficiency is low when the desired result is the smallest possible outlet temperature.

The most favorable result for the hot fluid outlet temperature occurs when the process is efficient and effective, however, with high efficiency assuming a more significant effect on the outcome for the outlet temperature of the hot fluid.

\section{Conflicts of Interest}

The author declares no conflicts of interest regarding the publication of this paper.

\section{References}

[1] Bejan, A. (1987) The Thermodynamic Design of Heat and Mass Transfer Processes and Devices. Heat and Fluid Flow, 8, 258-276. https://doi.org/10.1016/0142-727X(87)90062-2

[2] Fakheri, A. (2007) Heat Exchanger Efficiency. Transactions of the ASME, 129, 1268-1276. https://doi.org/10.1115/1.2739620

[3] Tiwari, R. and Maheshwari, G. (2017) Effectiveness and Efficiency Analysis of Parallel Flow and Counter Flow Heat Exchangers. IJAIEM, 6, 314-319.

[4] Emal, Q.M. and Elena, P. (2018) Overall Energy Balance and Heat Transfer in a Shell and Tube Heat Exchanger. Proceedings of ISER 109th International Conference, Ottawa, Canada, 27-28 February 2018, 9-17.

[5] Silaipillayarputhur, K. and Khurshid, H. (2019) The Design of Shell and Tube Heat Exchangers: A Review. IJMPERD, 9, 87-102. https://doi.org/10.24247/ijmperdfeb201910

[6] Qashqaei, A. and Asl, R.G. (2015) Numerical Modeling and Simulation of Copper Oxide Nanofluids Used in Compact Heat Exchangers. International Journal of $\mathrm{Me}$ chanical Engineering (IJME), 4, 1-8.

[7] Shankar, M.S., Immanuel, P. and Eswaran, M. (2018) Heat Transfer Analysis of Shell and Tube Heat Exchanger Using $\mathrm{Al}_{2} \mathrm{O}_{3}$ Nanofluids. International Journal of Mechanical Engineering and Technology (IJMET), 9, 980-989.

[8] Mahajan, R., et al. (2019) Enhancement of Convective Heat Transfer of Shell and Tube Heat Exchanger Using Nanofluids. IOSR Journal of Engineering (IOSR JEN), 8th National Conference on "Recent Developments in Mechanical Engineering" 
[RDME-2019], 55-58.

[9] Gore, P.S. and Kshirsagar, J.M. (2017) Heat Transfer Enhancement with $\mathrm{Al}_{2} \mathrm{O}_{3} \mathrm{Na}$ nofluid in Shell and Tube Heat Exchanger Using Twisted Tapes: A Review. IJSRD, 5, 184-191.

[10] Nogueira, É. (2020) The Effectiveness Method ( $\varepsilon$-NTU) to Analyze the Thermal Performance of the Flat Tube Multi-Louvered Finned Radiator with Silver Nanoparticles Suspension in Ethylene Glycol. International Journal of Advanced Technology and Engineering Exploration, 7, 102-112. https://doi.org/10.19101/IJATEE.2020.762040

[11] Cordeiro Jr., L.Z. and Nogueira, É. (2020) Influence of the Coolant Flow Containing Silver Nanoparticles (Ag) from an Aqueous Solution Based on Ethylene Glycol (EG50\%) on the Thermal-Hydraulic Performance of an Automotive Radiator. World Journal of Nano Science and Engineering, 10, 14-26. https://doi.org/10.4236/wjnse.2020.101002

[12] Nogueira, E. (2010) Thermal-Hydraulic Performance of Graphene Nanoribbon and Silicon Carbide Nanoparticles in the Multi-Louvered Radiator for Cooling Diesel Engine. Journal of Engineering Sciences, 7, F22-F29. 